\title{
School Alienation and Student Well-Being: A Cross-lagged Longitudinal Analysis
}

\author{
Julia Morinaj ${ }^{1}$ \\ University of Bern, Switzerland
}

Tina Hascher ${ }^{1}$

University of Bern, Switzerland

Corresponding author:

Julia Morinaj

iuliia.morinaj@edu.unibe.ch

Tel.: +41791714725

${ }^{1}$ Department of Research in School and Instruction, Institute of Educational Research, University of Bern, Fabrikstrasse 8, 3012 Bern, Switzerland

\section{Acknowledgements}

First and foremost, we thank the students and teachers who continue to support our efforts to investigate school alienation within the "School Alienation in Switzerland and Luxembourg (SASAL)" research project. We would also like to thank the school principals for giving us access to their teachers and students. Second, we would like to thank the research assistants who supported us during the data collection and data entry processes. We are grateful to the Swiss National Science Foundation (100019L_159979) in Switzerland and the Luxembourg National Research Fund (INTER/SNF/14/9857103) in Luxembourg for funding the SASAL project. 


\begin{abstract}
School alienation is identified as a severe educational problem that hampers students' academic journey. However, little is known about the concept's interplay with other socio-emotional phenomena such as well-being. This longitudinal study explored the cross-lagged associations among alienation from learning, teachers, and classmates, and different dimensions of student well-being. To investigate the direction of the relationship between school alienation and student well-being, we used self-report instruments at two measurement points over a 1-year interval. Data were collected from a sample of 508 Swiss secondary school students from grade 7 to grade 8 participating in the "School Alienation in Switzerland and Luxembourg (SASAL)" research project. Controlling for gender differences, the results of latent variable modeling revealed considerable stability effects across time and a causal effect of school alienation on student well-being, whereas the reversed effect of student well-being on subsequent school alienation was nonsignificant. The three domains of school alienation were found to have different associations with six well-being dimensions. Alienation from learning had a negative impact on positive attitudes to school and enjoyment in school. Alienation from teachers negatively predicted positive attitudes to school and positively predicted worries and social problems in school. Alienation from classmates influenced future positive attitudes to school and social problems in school. The findings provide empirical support for the importance of students' feelings of alienation in determining students' sense of well-being and imply that both academic and social aspects of schooling have a significant impact on young people's stances toward school.
\end{abstract}

Keywords: School alienation; Student well-being; Secondary school; Longitudinal design; Crosslagged panel models

\title{
Introduction
}

The schooling experience has a crucial impact on children and adolescents, because they spend a huge amount of time in schools, more than in any other place outside the home. On average, during formal schooling students receive about 7,500 hours of compulsory instruction in classroom settings (OECD 2016). Consequently, understanding the impact of schools on adolescents' socio-emotional development is an important educational task, which requires simultaneous consideration of the school context and students' subjective emotional and cognitive evaluations of the school environment.

The environment in which students learn influences their development and satisfaction with life. In particular, a school life that facilitates meaningful academic learning, in which adolescents can find a connection between learning at school and their social realities, promotes positive attitudes toward school (Altenbaugh et al. 1995; Konu and Rimpelä 2002). Also, supportive and stable social interactions with peers and teachers were found to be particularly important and beneficial for individuals' happiness and psychological well-being (Baumeister and Leary 1995; Hall-Lande et al. 2007), whereas a lack of positive and significant interpersonal relationships causes a variety of ill effects: low well-being, risk of maladjustment at school and mental health problems, peer exclusion, poor academic performance, depression, victimization from peers, delinquency or criminality, early school withdrawal, and even school alienation (Aikins et al. 2005; Bagwell et al. 1998; Buhs and Ladd 2001; Fenzel 2000; Gazelle and Druhen 2009; Author 2010; Prinstein et al. 2001; Wentzel et al. 2004). Therefore, investigating what happens to students in classroom environments and not exclusively their academic achievement is a clue to identifying the quality of schooling and formal education as well as the factors that contribute to individual growth and well-being.

\section{School alienation}

School alienation (SAL) has become a frequently examined stressor in adolescent life and represents a difficult educational problem that poses a significant challenge for schools and educational networks. Not only does it affect the quality of the schooling experience, but it is also accompanied by other school-related problems such as deviant behaviors, low participation in school, and dropping out (Alexander et al. 1997; Archambault et al. 2009; Brown et al. 2003; Eccles and Alfeld 2007; Eccles and Gootman 2002; Farrow 1991). Some scholars have shown that alienation is an inevitable part of education and may be viewed as a natural stage in adolescent development (Nutbeam et al. 1993; Sidorkin 2004). Other researchers have pointed to the severe problems associated with SAL, such as both physical and emotional disease (Farrow 1991). Student feelings of alienation, for example, tend to lessen student well-being (Dekel and Tuval-Mashiach 2012; Pyhältö et al. 2010; Rayce et al. 2008). 
The importance of student well-being (SWB), including adolescents' physical, mental, and emotional health status, is attracting widespread interest in research on adolescence. Promoting happiness and psychological wellbeing in school complements and enhances classroom learning (UNESCO 2016). A recent study on SWB showed that in most countries students are satisfied with their lives (OECD 2017). Nevertheless, a great number of students across different countries reported remarkably low levels of life satisfaction. Accordingly, SWB represents one of the most extensively researched constructs, increasingly incorporated into education policy (OECD 2017). Enhancing both SWB and academic competencies seems to be a relevant approach to becoming life-long learners and responsible citizens later in their life (Noble and McGrath 2016).

Alienation from school manifests itself in at least three school-related domains. First, alienated students may feel estranged from learning processes at school (Altenbaugh et al. 1995; Çağlar 2013). Such students see little relevance in learning for reaching better learning outcomes or becoming successful citizens. Often, individuals have to discard from their memory the "inconsequential ethos of schoolwork" acquired throughout their schooling years, and attain practical skills and attitudes useful for life as an adult (Sidorkin 2004). Students who are engaged in meaningful learning are less likely to feel alienated from the school system (Moriarty and McDonald 1991). Second, students may feel estranged from their teachers, the significant figures in the school system whose role it is to support and navigate their students during their learning journey (Altenbaugh et al. 1995). Teachers' failure to satisfy students' immediate needs or aspirations, for example a need for emotional support, can enhance students' alienation from teachers (Ifeagwazi et al. 2015; Kagan 1990; Pyhältö et al. 2010). In contrast, positive and supportive teacher-student interactions were found to alleviate student alienation (Ghaith et al. 2007; Author and Hagenauer 2010). Third, students may feel detached from their classmates. Quite often, students with disruptive behavior sharing similar negative attitudes toward school develop a distinctive subculture to represent resistance to schooling and are often rejected by classmates (Coie et al. 1990; Guerra et al. 1995). Feelings of nonbelonging and a lack of meaningful social interactions are strongly linked to decreased classroom participation and increased desire to avoid school (Buhs and Ladd 2001). Accordingly, based on these findings, students may become alienated from learning, teachers, classmates, and ultimately school as a whole, whereas students who do not experience feelings of alienation from school perceive their social interactions as positive and therefore identify themselves with the school system (Hyman et al. 2003).

Although we suppose that the reasons for SAL go far beyond the classroom, we have seen that the school environment in particular plays an essential role in this process. Here, SAL has been defined as the feeling of estrangement from the social and academic aspects of school life, namely learning, teachers, and classmates, and eventually school as a whole (Author and Hadjar 2017). In other words, students may become alienated from classmates, and/or teachers, and/or learning at school. Previous research has also shown that usually boys tend to be more alienated than girls (Hadjar and Lupatsch 2010; Author and Hagenauer 2010; Leduc and Bouffard 2017) and feelings of alienation tend to increase with grade level (Çağlar 2013; Author and Hagenauer 2010; Murdock 1999).

\section{School alienation and student well-being}

Findings on the relation between SAL and SWB reveal a negative association between the two constructs; that is, a higher SAL is connected to a lower SWB and vice versa. The alienated person lacks inner harmony, sincerity, authenticity, and personal well-being (Yonah 1997). For example, when students' learning needs are unsatisfied or when they face poor relationships with classmates and/or teachers, their psychological well-being decreases. Supportive, trusting, and higher-quality interpersonal relationships with peers and teachers are strongly linked to well-being outcomes and represent the most influential elements for reducing student alienation during adolescence (Baumeister and Leary 1995; Author 2003; Author and Hagenauer 2010; OECD 2017; Pyhältö et al. 2010). Human beings in general, and adolescents in particular, are in need of strong social connections and interactions with other people (Bond et al. 2007; Cacioppo and Patrick 2008; Greenberg et al. 1983; La Greca and Harrison 2005). Similarly, research on intimacy suggested that the quality of relatedness played a prominent role in individual well-being (Prager and Steil 1997; Reis and Shaver 1988). Furthermore, a large body of research demonstrated that feeling competent and autonomous was also highly associated with enhanced well-being (McGregor and Little 1998; Pinquart and Sörensen 2000; Rice et al. 1997; Ryan and Deci 2000). Self-efficacy, perceived control over one's activities, and important social relationships with peers and teachers regulate students' learning (Pyhältö et al. 2010), alleviating students' feeling of estrangement from learning processes in school and members of the school community (Ifeagwazi et al. 2015). Hence, it appears that the fulfillment of students' psychological and social needs, especially the quality of relationships with peers and teachers, is essential for SWB in school (Author and Hagenauer 2010; Reis et al. 2000; Ryan and Deci 2001). In alienation literature, the SWB-SAL link is examined less frequently and the direction of the relationship has been assumed rather than investigated.

Theoretical and empirical findings have demonstrated that SAL as well as SWB are complex multidimensional constructs, each consisting of several distinct but related domains (Author et al. 2017; Author 2007). As it is with the differentiation of negative and positive emotions (cf. Russell and Caroll 1999), the absence of alienation does not imply that a student feels well in school; similarly, the absence of student well-being does not imply that the 
student is alienated from school. Given the variety of emerging conceptualizations of SAL and SWB, this study suggests a more holistic approach taking the school context into account. Specifically, SAL incorporates three school-related domains, namely alienation from learning, from teachers, and from classmates, each comprising both emotional (i.e., students' feelings toward school) and cognitive (i.e., students' beliefs, perceptions, knowledge, assumptions, and judgments of school) aspects. This classification may bear some resemblance to previous theoretical propositions that in a school setting students can be alienated in academic and/or social domains (Tinto 1975, 1993). At the same time, we recognize the multidimensional nature of SWB (Author 2011, 2012) reflecting the theoretical construct of general well-being (Diener and Lucas 2000; Grob et al. 1996; Mayring 1991). This includes considering both positive and negative aspects of school life, because a school day offers a vast variety of situations in which to experience both positive and negative emotions. For example, students may simultaneously experience worries related to academic achievement pressure along with joy from interactions with peers. Accordingly, SWB has been conceptualized as the prevalence of students' positive emotions and cognitions over negative ones toward school life and members of the school community (Author 2003). The construct involves emotional (emotions in school), cognitive (attitudes toward school), and physical (physical condition in school) elements. Specifically, six dimensions constitute SWB in school: positive attitudes toward school, enjoyment in school, positive academic self-concept, worries in school, physical complaints in school, and social problems in school. Three positive and three negative dimensions represent particular aspects of SWB and can be used as indicator categories. SWB may be influenced by the quality of school and teaching, social relationships in school, current emotions and cognitions, personality factors, learning background, and previous experiences.

Several cross-sectional studies have demonstrated that higher levels of SAL are generally related to lower levels of SWB (Dekel and Tuval-Mashiach 2012; Farrow 1991; Moreno and de Roda 2003; Osin 2009; Pyhältö et al. 2010; Rayce et al. 2008; Safipour et al. 2011). However, the reverse causal order is also discussed; that is, alienation may be predicted by SWB (Vahedi and Nazari 2011), viewing the latter as a means of alleviating the problem of student alienation. Some researchers merely mentioned the existent correlation between SAL and SWB, without specifying the direction of the relationship. Yet, most studies exploring the impact of alienation apply a cross-sectional design, which does not reveal the direction of the association between the two constructs. Measuring variables at one point in time may only reveal association, while the direction of causality remains unclear. The research so far has not tested the possibility of reversed or mutual causation between SAL and SWB. For example, students experiencing low well-being may be more alienated from school. It is also plausible that individuals who feel alienated from school may be less satisfied at school, and a lack of happiness in school causes them to experience even more SAL. Therefore, there is a need for longitudinal studies to advance knowledge about the causal relationship between SAL and SWB (Safipour et al. 2011; Rayce et al. 2008). Understanding the relationship between the two phenomena may contribute to the design of school-based prevention strategies aimed at alleviating the problem of SAL and increasing SWB and academic success, or at least counteracting a decline in SWB and success in school.

Applying a longitudinal design can be a fruitful way to investigate the direction of the relationship between SAL and SWB. Indeed, confronting issues of causality as well as examining the temporal effects of SAL raises an important and interesting topic for current and future research on SAL. Hence, the primary purpose of this study was to explore associations among self-reported SAL domains and SWB dimensions across two measurement points. Specifically, we examined the correlations between SAL and SWB at each of two time points, the temporal stability of SAL and SWB, and their cross-lagged effects (i.e., effects of SAL on SWB and vice versa) across time. Drawing upon existing research on SAL and SWB and the exploratory nature of this study, we tested whether student feelings of alienation lead to lower well-being over time or whether low SWB leads to subsequent SAL. To test a hypothesis about causal directionality as well as the development of SAL and SWB across the two time points, we applied a cross-lagged panel design using the latent variable approach (Newsom 2015; Selig and Little 2012). Three sets of cross-lagged analyses - for alienation from learning, teachers, and classmates - across the six aspects of SWB were conducted to allow for more rigorous testing. Given the exploratory nature of this study, we did not specify any particular set of hypotheses.

\section{Method}

\section{Participants and procedures}

In the present study, we used data from the first and second waves of the binational research project School Alienation in Switzerland and Luxembourg (SASAL, 2015-2018), which focuses on the development, causes, and consequences of SAL in primary and secondary education. One part of the study reported here focuses on exploring the development of SAL and SWB as well as longitudinal associations between the two constructs among secondary school students.

The first wave $\left(t_{1}\right)$ comprised 550 students from grade $7\left(45.2 \%\right.$ male; $M_{\text {age }}=13.0$ years $\left.[S D=.55]\right)$ from the Swiss canton of Bern. The second wave $\left(t_{2}\right)$ consisted of 540 students from grade $8\left(45.6 \%\right.$ male; $M_{\text {age }}=14.0$ years $[S D=.57])$. The analytic sample consisted of 508 secondary school students who responded to both waves of the study. Students were recruited on a voluntary basis and were assured of complete anonymity and confidentiality, 
specified in a written parental consent form. A paper-and-pencil questionnaire was administered to students in their classrooms by trained members of a research team during regular school time at two measurement points. It took around 90 minutes to complete the survey. No data imputation was applied.

\section{Measures}

School Alienation was measured using 24 items from the recently developed School Alienation Scale (SALS; Author and Hadjar 2017). The items assess secondary school students' feelings and thoughts toward learning, teachers, and classmates, and represent the three domains of SAL. The SALS was validated across the Swiss and the Luxembourgish primary and secondary school students and across gender, and was found to have strong psychometric properties (Author et al. 2017). Alienation from Learning (e.g., "I don't find pleasure in learning at school"; $\alpha_{t 1}=.88, \alpha_{t 2}=.86$ ), Alienation from Teachers (e.g., "I do not feel taken seriously by my teachers"; $\alpha_{t 1}=$ $.79, \alpha_{t 2}=.85$ ), and Alienation from Classmates (e.g., "In my class I feel like someone who doesn't fit in"; $\alpha_{t 1}=$ $\left..83, \alpha_{t 2}=.80\right)$ consisted of eight items each. All SALS items were scored from $1=$ disagree to $4=$ agree.

To assess student well-being, we used a 19-item version of the Student Well-Being Questionnaire (SWBQ; Author 2007). The scale addresses various situations in school and includes the six dimensions of well-being. The SWBQ was validated in four European countries, namely, Germany, German-speaking Switzerland, the Czech Republic, and the Netherlands (Author 2007), thereby supporting the notion of the cultural generalizability of the instrument. Three positive and three negative dimensions comprised the scale: Positive attitudes toward school (PAS, 3 items, e.g., "I like to go to school"; $\alpha_{t 1}=.77, \alpha_{t 2}=.79$ ), Enjoyment in school (EIS, 3 items, e.g., "Have you experienced joy because of teachers' friendliness in the past few weeks?"; $\alpha_{t 1}=.73, \alpha_{t 2}=.81$ ), Positive academic self-concept (PASC, 3 items, e.g., "I don't have problems mastering school tasks"; $\alpha_{t 1}=.79, \alpha_{t 2}=.80$ ), Worries in school (WIS, 3 items, e.g., "Have you been worried about your school grades in the past few weeks?"; $\alpha_{t 1}=.76, \alpha_{t 2}=.78$ ), Physical complaints in school (PCS, 4 items, e.g., "Have you had a severe headache in school in the past few weeks?"; $\alpha_{t 1}=.75, \alpha_{t 2}=.81$ ), and Social problems in school (SPS, 3 items, e.g., "Have you had problems with your classmates in the past few weeks?"; $\alpha_{t 1}=.81, \alpha_{t 2}=.84$ ). A factor analysis confirmed the proposed subscale structure (Author 2007). The items were scored from $1=$ never to $6=$ very often.

In terms of missing values, there was a negligible amount of missing questionnaire data due to student nonresponse (less than $0.6 \%$ and $1 \%$ of missing data at the item level for SAL and SWB scales, respectively), ensuring robust data analysis (Acuña and Rodriguez 2004).

\section{Analysis strategy}

Prior to conducting statistical analyses, we tested the appropriateness of a cross-lagged panel design and investigated whether SAL and SWB are rather individually experienced phenomena. To evaluate the degree of dependence of SAL and SWB on class membership, we estimated the total variation at both individual and classroom levels by fitting a two-level model with students nested within classrooms. The intraclass correlation coefficients indicated that only $16 \%, 14 \%$, and $12 \%$ of the total variance in alienation from learning, teachers, and classmates at wave 1, respectively, can be attributed to differences between classrooms $(17 \%, 10 \%$, and $9 \%$ at wave 2). Most variation in SWB dimensions (91-97\%) was attributed to within-classroom differences. A considerable amount of variability at individual level raises questions about the possible differential importance of classroom characteristics for enhancing or reducing SWB and SAL, implying that SWB and SAL are rather individually experienced phenomena. Thus, cross-lagged panel models focusing on the individual standings on the construct across time has been seen as a relevant approach.

The analytic procedure included two major steps. First, as a commonly accepted practice, we assessed the factorial invariance across the two measurement occasions, designed to evaluate temporal change in a construct (Brown 2015; Newsom 2015). Assessing measurement equivalence through a series of models, we examined whether the latent variables, namely SAL and SWB, each possessed the same psychometric characteristics over time (Milfont and Fischer 2010). We first examined nonrestricted models with freely estimated factor loadings only requiring the same factor structure on both testing occasions, serving as baseline models. In the next step, we imposed equality constraints for corresponding factor loadings across time. The fit of this model was subsequently compared to a nonrestricted model on the basis of chi-square difference testing using the Satorra-Bentler scaled chi-square (Satorra and Bentler 2001). A nonsignificant chi-square difference test indicates invariance between the nonrestricted and restricted models. Furthermore, in compliance with the recommendations for testing measurement invariance (Chen 2007), a change of $\geq .01$ in the comparative fit index (CFI) indicates noninvariance. Residuals of the same measured variables were allowed to correlate over time in all models.

After establishing the adequacy of the measurement models, in the second step of the analyses, we verified the complete model, including the structural associations among the SAL domains and SWB dimensions across time (see Fig. 1). Cross-lagged panel analysis allows autoregressive and cross-lagged paths to be explored at the same time, together with cross-sectional correlations between the constructs. For each subscale combination, we simultaneously evaluated the stability, SAL $\rightarrow$ SWB, SWB $\rightarrow$ SAL, and bidirectional pathways, estimating 18 
smaller models. The software package Mplus Version 7.31 was used for all statistical analyses using raw data (Muthén and Muthén 1998-2012). All models were estimated applying the maximum likelihood procedure with robust standard errors (MLR). Considering an adequate sample size in the present study $(N>300$; Chen 2007), model fit was assessed based on several fit indices, including the $\chi^{2} / d f$ ratio, the comparative fit index (CFI), the root mean square error of approximation (RMSEA), and the standardized root mean square residual (SRMR). The following threshold values were applied: $\chi^{2} / d f<2$ (Schermelleh-Engel et al. 2003), CFI $\geq .90$ (Homburg and Baumgartner 1995; Little 2013), RMSEA and SRMR of close to .05 (Hu and Bentler 1999; Schermelleh-Engel et al. 2003). The Satorra-Bentler scaled chi-square was used for chi-square difference testing for nested models that have to be applied for classroom testing. Residuals of the same measured variables were allowed to correlate over time in all models.

Grade 7

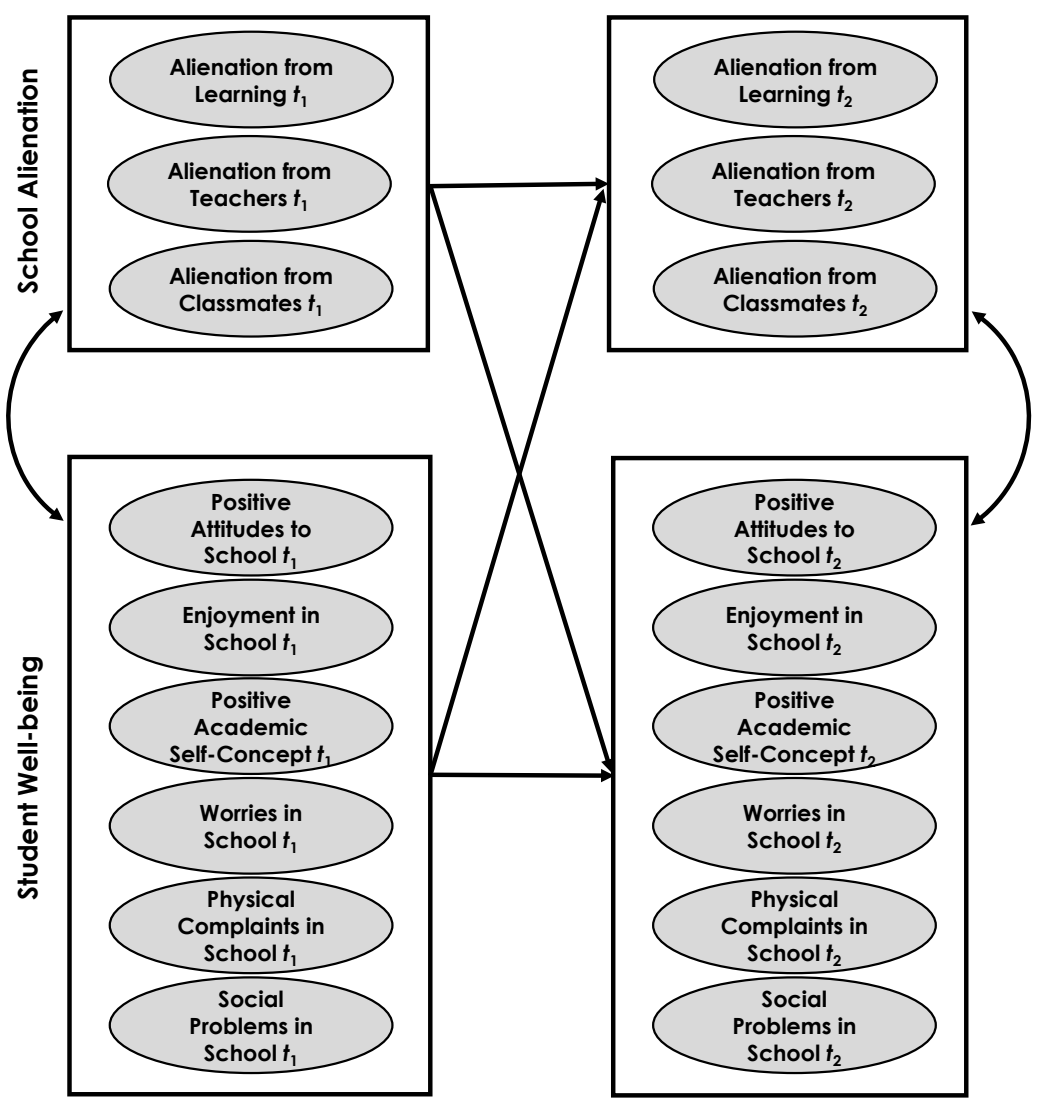

Fig. 1 Hypothesized cross-lagged panel model of the relationship between domains of school alienation and dimensions of student well-being between grade $7\left(t_{1}\right)$ and grade $8\left(t_{2}\right)$

\section{Results}

\section{Descriptive statistics}

Descriptive data for the variables used in the study in wave 1 and 2 are presented in Appendix 1. The pattern of correlations was as expected. The SAL scales correlated negatively with positive dimensions of SWB measured both simultaneously and over time, and positively with negative SWB dimensions. Strong positive attitudes toward school were associated with reduced alienation from learning. Furthermore, social problems in school were moderately positively correlated with alienation from classmates. The correlations of the school alienation scales across time were moderate to high.

The results of a repeated measures multivariate analysis of variance (MANOVA) did not reveal a statistically significant change in students' alienation from classmates $(p=.09)$ between grade 7 and grade 8 , yet the level of student alienation from teachers and learning significantly increased across time $(F(1,504)=15.87, p<.05$, partial $\eta^{2}=.03$ and $F(1,504)=11.74, p<.05$, partial $\eta^{2}=.02$, respectively). 


\section{Longitudinal measurement invariance}

Separate measurement models were designed for each SAL domain across the six SWB dimensions over the two measurement occasions. The specified models fitted the data very well. Tests of factorial invariance for each SAL domain and all SWB dimensions revealed the equality of item factor loadings across the two waves. The chisquare difference tests between the nonrestricted ( $1 \mathrm{a}-6 \mathrm{a})$ and more constrained $(1 \mathrm{~b}-6 \mathrm{~b})$ models were statistically nonsignificant, indicating that both models fit statistically equally well, except for the two models, the chi-square difference test between the nonrestricted and restricted models (Alienation from classmates-Enjoyment in School and Alienation from learning-Enjoyment in School) yielded a significant difference $\left(\Delta \chi^{2}=23.15, \Delta d f=8, p<\right.$ $.01 ; \Delta \chi^{2}=27.62, \Delta d f=9, p<.01$, respectively) and a slightly worse fit. However, given the sensitivity of the chisquare measure to sample size, it can be concluded that there was no substantial difference between the two models (see Ong and van Dulmen 2006). This means that measurement models of SAL domains and dimensions of SWB are viable on both testing occasions, providing support for longitudinal measurement invariance. In other words, we established a cross-time measurement invariance, meaning that the constructs of SAL and SWB work equally well across time. The fit indices of all the models are demonstrated in Appendix 2.

\section{Gender differences}

In order to test for gender differences in the mean scores of SAL domains and SWB dimensions, we applied $t$ tests. The results indicated that gender had a significant effect on students' feelings of alienation from classmates, teachers, and learning in grade 7: Boys had a higher mean score in all three SAL domains than girls, $t(495)=-$ $3.77, p=.000$, Cohen's $d=0.35 ; t(495)=-3.69, p=.000, d=0.32$; and $t(496)=-2.74, p=.006, d=0.23$, respectively. In grade 8 , boys were also more alienated from school than girls: $t(502)=-3.51, p=.000, d=0.31$ for alienation from classmates; $t(502)=-2.61, p=.009, d=0.23$ for alienation from teachers; and $t(502)=-4.09$ $p=.000, d=0.37$ for alienation from learning. In regard to SWB, the results revealed that female participants had statistically significantly more worries and physical complaints in school than male students in grade $7(t(497)=$ $2.39, p=.017, d=0.21$ and $t(497)=3.57, p=.000, d=0.32$, respectively). However, in grade 8 , a significant gender difference was found only in regard to physical complaints in school: Girls reported more physical complains than boys $(t(502)=5.61, p=.000, d=0.51)$. No systematic gender differences were found with respect to other SWB dimensions.

\section{Cross-lagged panel models}

Separate cross-lagged panel models, constrained in accordance with the established factorial invariance, were specified to investigate the structural relations between SAL domains and SWB dimensions across time. We imposed several equality constraints upon all models: Factor loadings for repeated indicators were constrained to be equal over time, and correlated measurement residuals among repeated indicators were included. All statistically nonsignificant paths and covariances were eliminated from the final models one by one. The fit statistics for the final cross-lagged models are shown in Table 1. 
Table 1 Results of cross-lagged structural models for school alienation domains and student well-being dimensions

\begin{tabular}{|c|c|c|c|c|c|}
\hline Model & $\chi^{2}$ & $d f$ & CFI & RMSEA & SRMR \\
\hline \multicolumn{6}{|c|}{ Alienation from learning } \\
\hline AL - PAS & 385.32 & 190 & .94 & .05 & .05 \\
\hline AL - EIS & 368.45 & 190 & .96 & .04 & .05 \\
\hline AL - PASC & 368.49 & 191 & .96 & .04 & .05 \\
\hline AL - WIS & 348.74 & 191 & .96 & .04 & .05 \\
\hline $\mathrm{AL}-\mathrm{PCS}$ & 392.29 & 234 & .97 & .04 & .05 \\
\hline AL - SPS & 383.01 & 191 & .96 & .04 & .05 \\
\hline \multicolumn{6}{|l|}{ Alienation from teachers } \\
\hline AT - PAS & 325.04 & 202 & .96 & .04 & .05 \\
\hline AT - EIS & 352.68 & 202 & .95 & .04 & .05 \\
\hline AT - PASC & 306.38 & 203 & .96 & .03 & .04 \\
\hline AT - WIS & 297.18 & 202 & .97 & .03 & .04 \\
\hline AT - PCS & 338.65 & 246 & .97 & .03 & .05 \\
\hline AT - SPS & 312.27 & 202 & .96 & .03 & .04 \\
\hline \multicolumn{6}{|c|}{ Alienation from classmates } \\
\hline AC - PAS & 343.84 & 163 & .93 & .05 & .06 \\
\hline AC - EIS & 364.63 & 164 & .93 & .05 & .06 \\
\hline AC - PASC & 270.25 & 164 & .96 & .04 & .05 \\
\hline AC - WIS & 256.90 & 164 & .96 & .03 & .05 \\
\hline $\mathrm{AC}-\mathrm{PCS}$ & 298.61 & 203 & .97 & .03 & .05 \\
\hline AC - SPS & 386.81 & 163 & .93 & .05 & .06 \\
\hline
\end{tabular}

$A L$ alienation from learning, $A T$ alienation from teachers, $A C$ alienation from classmates, $P A S$ positive attitudes to school, $E I S$ enjoyment in school, $P A S C$ positive academic self-concept, WIS worries in school, $P C S$ physical complaints in school, $S P S$ social problems in school, $C F I$ comparative fit index, RMSEA root mean squared error of approximation, SRMR standardized root mean square residual

\section{Alienation from learning and student well-being}

With regard to alienation from learning, it was shown that student feelings of alienation from learning in grade 7 significantly negatively predicted positive attitudes to school $(\beta=-.35, p<.001)$ and enjoyment in school $(\beta=-.20, p<.01$; see Fig. 2$)$ in grade 8 . The overall fit of the models was good (see Table 1$)$. The total variance accounted for in alienation from learning, positive attitudes to school, and enjoyment in school at $t_{2}$ was approximately $54 \%, 36 \%$, and $31 \%$, respectively. The reverse effects did not reach significance. The specified constructs exhibited relatively high stability between the two measurement points. In addition, the results indicated robust negative synchronous correlations between alienation from learning and positive attitudes to school $(r=$ -.75 and $r=-.78, p<.001$, respectively).
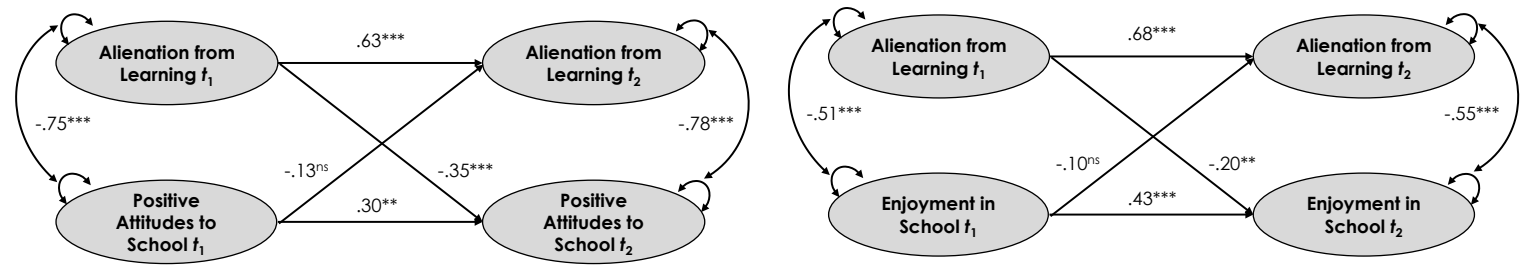

Fig. 2 Standardized parameter estimates for the cross-lagged model of the relations between alienation from learning and student well-being dimensions at grades $7\left(t_{1}\right)$ and $8\left(t_{2}\right)$ $* * * p<.001, * * p<.01, * p<.05, n s$ nonsignificant

\section{Alienation from teachers and student well-being}

Students feeling alienated from teachers at $t_{1}$ reported less positive attitudes to school $(\beta=-.13, p<.05)$, more worries in school $(\beta=.12, p<.05)$, and more social problems in school $(\beta=.16, p<.01)$ at $t_{2}$ (see Fig. 3). All 
models suggested a very good fit to the data (see Table 1). The estimated models account for $38 \%$ of the observed variability in alienation from teachers and for $32 \%$ in positive attitudes to school, $26 \%$ in worries in school, and $17 \%$ in social problems in school in grade 8 . A reversed negative relationship emerged between student enjoyment in school at $t_{1}$ and alienation from teachers at $t_{2}$ : The higher the student enjoyment was in grade 7 , the less alienated from teachers they were in grade $8(\beta=-.11, p<.05)$. However, the causal relationship between alienation from teachers at $t_{1}$ and enjoyment in school at $t_{2}$ was not significant $(\beta=-.10, p>.05)$. This model accounts for over a third of the variance in alienation from teachers $\left(R^{2}=.39\right)$ and for $29 \%$ of the variance in enjoyment in school in grade 8 . The autoregressive coefficients for alienation from teachers and specified well-being dimensions indicated that individual differences in these constructs were relatively stable over a 1-year lag between the measurement occasions.
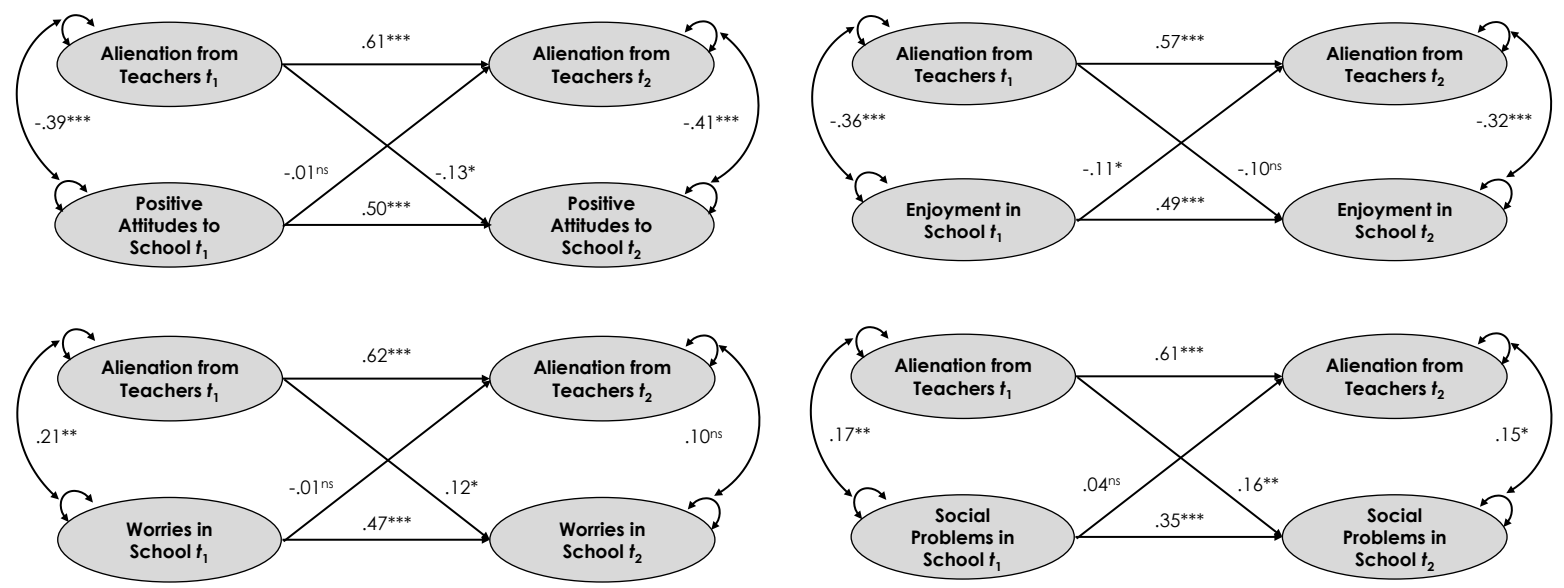

Fig. 3 Standardized parameter estimates for the cross-lagged model of the relations between alienation from teachers and student well-being dimensions at grades $7\left(t_{1}\right)$ and $8\left(t_{2}\right)$

$* * * p<.001, * * p<.01, * p<.05$, ns nonsignificant

\section{Alienation from classmates and student well-being}

With respect to the cross-lagged paths between alienation from classmates and the dimensions of SWB, we observed a significant negative effect of alienation from classmates at $t_{1}$ on positive attitudes to school at $t_{2}$ $(\beta=-.10, p<.05)$. The model accounts for nearly half of the variance in alienation from classmates $\left(R^{2}=.42\right)$ and for a third of the variance in positive attitudes to school $\left(R^{2}=.32\right)$ in grade 8 . In other words, alienation from classmates and positive attitudes to school jointly in grade 7 explain $42 \%$ of the variance in alienation from classmates and $32 \%$ of the variance in positive attitudes to school in grade 8 . The results also revealed a positive effect of alienation from classmates at $t_{1}$ on social problems in school at $t_{2}(\beta=.33, p<.001)$. This model accounts for $42 \%$ of the variance in alienation from classmates and $23 \%$ in social problems in school in grade 8 . However, neither of the reverse paths between positive attitudes to school and social problems in school at $t_{1}$ and alienation from classmates at $t_{2}$ reached significance $(\beta=.07, p>.05$ and $\beta=-.05, p>.05$, respectively). According to the fit indices (see Table 1), both models exhibited good fit to the data (see Fig. 4). Quite sizable autoregressive coefficients indicated relatively little change in individuals' standings on the constructs over time (Selig and Little 2012). The cross-lagged effects between alienation from classmates and all other SWB dimensions were not significant.
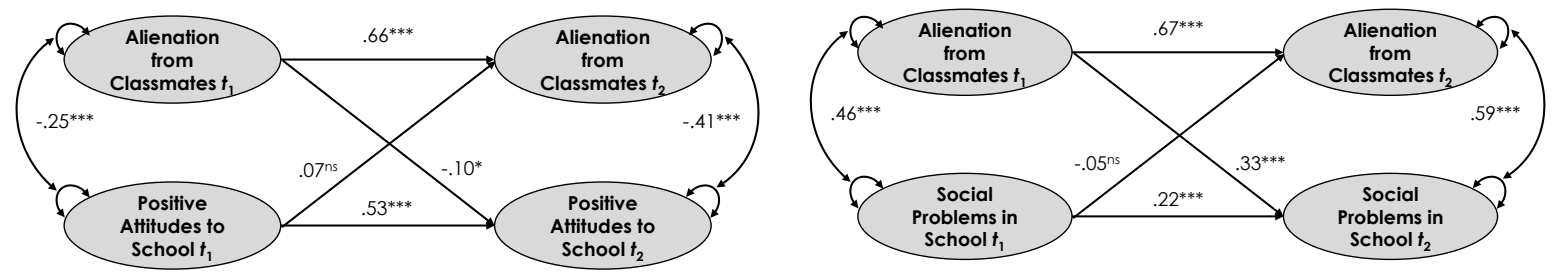

Fig. 4 Standardized parameter estimates for the cross-lagged model of the relations between alienation from classmates and student well-being dimensions at grades $7\left(t_{1}\right)$ and $8\left(t_{2}\right)$

$* * * p<.001, * * p<.01, * p<.05$, ns nonsignificant 


\section{Gender differences}

Several follow-up analyses were conducted to control for possible gender differences in associations between the SAL domains and SWB dimensions. In all the measurement models, the factor loadings were invariant across male and female students, indicating that the constructs are identically defined in both groups and across time. Multigroup analysis was used to compare male and female models simultaneously by constraining stability and cross-lagged paths to be equal across gender. We further tested a decrease in model fit using chi-square difference tests. These gender-restricted models differed significantly from the nonrestricted models, indicating that the stability and cross-lagged paths differ across the two subsamples (e.g., $\Delta \chi^{2}(4)=38.75, p<.01$ for the Alienation from Classmates and Positive Attitudes to School cross-lagged model).

\section{Summary}

To summarize, the results of the cross-lagged panel models, in which we specified reciprocal relationships between SAL domains and SWB dimensions over time, supported the causal effect of SAL on subsequent SWB, rather than the reverse causation and mutual effects. A reverse negative relationship was found only between student enjoyment in school in grade 7 and alienation from teachers in grade 8 . All autoregressive effects were substantial and significant $(p<.001)$. In regard to cross-sectional associations, higher student alienation rates were associated with lower positive attitudes to school as well as enjoyment in school and higher levels of worries in school and social problems in school. The longitudinal associations between SAL domains and SWB dimensions differ between male and female students. Although SAL was not found to be associated with all dimensions of SWB (no effect on positive academic self-concept and physical complaints in school), the present analyses identified some valuable associations that warrant further research.

\section{Discussion and conclusion}

This study applied a cross-lagged longitudinal design to examine the developmental dynamics between SAL and SWB among secondary school students taking gender differences into account. We attempted to expand the understanding of how SAL causally relates to SWB and vice versa. The relation between these two constructs is evident (e.g., Author and Hagenauer 2010; Pyhältö et al. 2010), but the direction of the relationship has not yet been systematically investigated. Although most existing studies support a negative association between SAL and SWB (e.g., Dekel and Tuval-Mashiach 2012; Moreno and de Roda 2003; Safipour et al. 2011), the relationship between the constructs was based on data collected at a single point in time, leaving the direction of causality an unresolved issue. To the best of our knowledge, no longitudinal studies have examined the association between SAL and SWB, and no study has addressed this issue using a cross-lagged panel design. We therefore tested for cross-lagged associations between the two constructs. Though the findings in this study must be considered exploratory, they do suggest important implications for further research.

The results of the latent variable cross-lagged analysis, after controlling for autoregressive effects and cross-sectional covariances, were generally consistent with the assumption that higher levels of SAL predict lower SWB (Dekel and Tuval-Mashiach 2012; Farrow 1991; Moreno and de Roda 2003; Osin 2009; Pyhältö et al. 2010; Rayce et al. 2008; Safipour et al. 2011). Most variation in SAL domains as well as SWB dimensions was attributed to within-classroom differences, implying that both SAL and SWB are rather individually experienced phenomena. Of particular note is the multidimensional nature of both constructs, meaning that different domains of SAL can have different associations with SWB dimensions. Our findings suggested that alienation from learning negatively predicted positive attitudes to school and enjoyment in school. In addition, the results indicated a strong negative correlation between alienation from learning and positive attitudes to school at both measurement points. We propose that alienation from learning and positive attitudes to school are two distinct, yet intercorrelated constructs. The first represents individual's disconnection from learning activities or a superficial approach to learning (academic alienation). It specifically reflects negative emotions and cognitions toward learning in school which may be provoked by instruction. The latter specifies students' attitudes toward school and education in general with items such as "I like to go to school". Furthermore, considering learning as the main objective of schooling and assuming that meaningful academic learning would result in more positive attitudes toward school, we therefore refer to academic learning as a predictor of students' attitudes toward school. Put differently, alienation from learning most likely due to the absence of meaningful learning predicts students' negative attitudes toward school in general. The study results reported here confirmed this direction of relationship: student feelings of alienation from learning significantly negatively predicted positive attitudes to school. The robust negative correlations can be explained by the overlap between students' attitudes toward learning as such and their attitudes toward school as an educational institution in such a way that learning represents the major objective of schooling. Although conceptually distinct, alienation from learning and positive attitudes to school both could be interpreted by students in a similar fashion. Alienation from teachers negatively predicted positive attitudes to school, and positively predicted worries in school, and social problems in school. Alienation from 
classmates was negatively related to subsequent positive attitudes to school and positively related to subsequent social problems in school. Neither of the effects of SWB dimensions on subsequent SAL reached significance, except for the reverse effect of student enjoyment in school and future alienation from teachers. Significant gender differences were found in students' feelings of alienation from learning, teachers, and classmates. In accordance with the literature (Hadjar and Lupatsch 2010; Author and Hagenauer 2010; Leduc and Bouffard 2017), boys were more alienated than girls. The multigroup models demonstrated that the proposed pattern of relationships differed across male and female students. Given that associations between SAL domains and SWB dimensions may develop differently over time, additional relationships also seem plausible. For example, the one-year time lag could be appropriate for revealing the effects of SAL on certain SWB dimensions, but either too short or too long for the detection of effects on other aspects of student school life (see Jonge et al. 2001 and Sher et al. 1996, for the importance of time intervals between measurement points). Hence, future research could broaden our understanding of how SAL relates to various facets of SWB over a longer period of time.

Our findings present several theoretical implications. The present study enhances previous research on the relationship between SAL and SWB that has not explicitly addressed the direction of the relationship. Moreover, we have shown that student feelings of alienation represent a crucial factor in determining students' sense of wellbeing, which is of vital importance to individuals, schools, and society in general (Author 2010; UNESCO 2016). Investigating the ways in which student alienation from learning, teachers, and classmates can be avoided or at least reduced, is an important topic for teachers and schools as well as education policy. However, we need to keep in mind the high stability of the constructs and that it takes time and effort to alleviate feelings of SAL among students (Ghaith et al. 2007).

The present study also has important practical implications. Based on the results, social problems in school were strongly predicted by alienation from classmates and teachers. This finding suggests that building supportive and stable social relationships with peers and teachers deserves particular attention, thereby confirming existing theoretical and empirical findings (Baumeister and Leary 1995; Hall-Lande et al. 2007). Moreover, worries in school were predicted by alienation from teachers. As students move to secondary school, often their worries and fears are centered around grades and performance, especially when students are exposed to a competitive learning environment (Anderman et al. 1998). Schools contribute significantly to the fears and anxieties of the adolescent population by emphasizing the importance of grades and comparing individuals' performance levels. As teachers play an essential role in these processes, not surprisingly, students perceive their teachers as decisive and controlling elements over learning outcomes (Harter et al. 1992). Closer inspection of school learning environments would be beneficial for enriching educational outcomes. Another essential finding that students' positive attitudes to school were predicted by all three SAL domains indicated that both social and academic aspects of schooling have a significant impact on young people's stances toward school. Accordingly, SWB can be promoted by nurturing healthy social interactions with classmates and teachers at school and establishing school environments that favor meaningful academic learning.

Given the high importance of SWB and for the purpose of handling students' feelings of alienation at schools, evaluations of the costs and benefits of incorporating well-being activities in school curricula might be of particular value. Research evidence constitutes the significance of intervention at the policy and school levels (UNESCO 2016). In addition, fostering SWB complements the traditional purposes of classroom learning and is highly recommended by experts in positive psychology (e.g., Seligman et al. 2009). Stressing well-being would promote not only students' enjoyment and engagement in school, but also their learning outcomes. At the same time, teachers' professional skills in supporting student learning and personal growth should be an issue, because they play a crucial role in the lives of most students (OECD 2017). Effective training could help teachers feel more confident in dealing with challenging situations and promoting SWB. Evidence from the UNESCO report on "happy" schools indicated a clear need for time (on extracurricular activities or more engaging teaching and learning methods) and space (e.g., for students - to express themselves and develop their talents and interests; for teachers - to try out other forms of classroom organization, such as outdoor classrooms or adaptable learning environments (flexible tables and seating options)) for both students and teachers to promote happiness and wellbeing in schools (UNESCO 2016). Nowadays, online tools also provide a variety of informative and useful recourses on SWB for educators, students, and parents (e.g., www.mindfulnessinschools.org, www.studentwellbeinghub.edu.au, www.minded.org.uk).

Despite significant findings on SAL and SWB, we have to highlight several potential limitations of the present study. First, our findings do not prove causality. The structural equation results revealed valuable associations that contribute to further research; however, having only two variables in the models and given that causality requires a complete picture of potential sources of influence, the present findings require additional supporting evidence (Selig and Little 2012). Moreover, cultural context can play a major role in influencing individuals' perception and understanding of survey questions. Given the exploratory nature of the current study and the fact that it was conducted in a particular cultural setting, replication studies with other cultural groups could be beneficial for generalization purposes. It would also be advantageous to include data collection from other sources in the school system, to capture the views of different actors, for example school principals or teachers. Teachers have rich experience in producing professional judgments about their students' functioning in school that can add significant value to student responses. Data could be collected using mixed methods such as cognitive interviews and group 
discussions. Parents' attitudes as an additional perspective could also enhance our understanding of students' stances, because family and home play a vital role in young people's lives (Field and Hoffman 1999; GonzalezDeHass et al. 2005; Gottfried et al. 1998). The alienation and well-being research could also benefit from longitudinal studies aimed at identifying the types of classroom interventions that would reduce feelings of SAL and at the same time improve SWB. Finally, as the study results did not confirm that SWB was a predictor of SAL, the causes of SAL need to be addressed by future research. For example, a significant decline in students' interest in learning and academic motivation during early adolescence (Eccles et al. 1993), negative student-teacher interactions (Hascher and Hagenauer 2010), poor peer relationships (Buhs and Ladd 2001), the probability of experiencing academic failure (Heimer and Matsueda 1997), the selection and ability grouping pressure (Betts and Shkolnik 2000), classroom characteristics (e.g., class size, socio-emotional climate), or negative attitudes of parents and friends toward school (Kocayörük and Simsek 2015; Murdock 1999) may be considered as potential causes of SAL.

In light of these limitations, this study has a number of strengths, including a longitudinal design that allows the direction of causality to be tested. Our findings support the notion that SAL leads to SWB over time and not vice versa. Although the three domains of SAL were shown to have different associations with various SWB dimensions, the present findings confirm the existing research. Thus, theoretically, the results support the relevance between the two constructs. In addition, the support for measurement model equivalence across time implies that the constructs were measured consistently on both measurement occasions. From a practical viewpoint, the results underpin the importance of positive and significant social interactions with peers and teachers at school and meaningful academic learning in promoting SWB.

\section{References}

Acuña, E., \& Rodriguez, C. (2004). The treatment of missing values and its effect on classifier accuracy. In D. Banks, F. R. McMorris, P. Arabie, \& W. Gaul (Eds.), Classification, clustering, and data mining applications (pp. 639-647). Springer Berlin Heidelberg.

Aikins, J. W., Bierman, K. L., \& Parker, J. G. (2005). Navigating the transition to junior high school: The influence of pre-transition friendship and self-system characteristics. Social Development, 14, 42-60.

Alexander, K. L., Entwisle, D. R., \& Horsey, C. S. (1997). From first grade forward: Early foundations of high school dropout. Sociology of education, 70(2), 87-107.

Altenbaugh, R. J., Engel, D. E., \& Martin, D. T. (1995). Caring for kids: A critical study of urban school leavers. London: The Falmer Press.

Anderman, E. M., Griesinger, T., \& Westerfield, G. (1998). Motivation and cheating during early adolescence. Journal of Educational Psychology, 90(1), 84-93.

Archambault, I., Janosz, M., Morizot, J., \& Pagani, L. (2009). Adolescent behavioral, affective, and cognitive engagement in school: Relationship to dropout. Journal of school Health, 79(9), 408-415, https://doi.org/10.1111/j.1746-1561.2009.00428.x

Bagwell, C., Newcomb, A., \& Bukowski, W. (1998). Preadolescent friendship and peer rejection as predictors of adult adjustment. Child Development, 69, 140-153.

Baumeister, R. F., \& Leary, M. R. (1995). The need to belong: desire for interpersonal attachments as a fundamental human motivation. Psychological bulletin, 117(3), 497-529.

Bond, L., Butler, H., Thomas, L., Carlin, J., Glover, S., Bowes, G., \& Patton, G. (2007). Social and school connectedness in early secondary school as predictors of late teenage substance use, mental health, and academic outcomes. Journal of Adolescent Health, 40(4), 357.e9 -357.e18, https://doi.org/10.1016/j.jadohealth.2006.10.013

Bornstein, M. H., Davidson, L., Keyes, C. L. M., \& Moore, K. A. (2003). Well-Being Positive Development Across the Life Course. Mahwah: Lawrence, Erlbaum Associates.

Brown, T. A. (2015). Confirmatory factor analysis for applied research. New York: Guilford Publications.

Brown, M. R., Higgins, K., \& Paulsen, K. (2003). Adolescent alienation what is it and what can educators do about it? Intervention in School and Clinic, 39(1), 3-9, https://doi.org/10.1177/10534512030390010101

Buhs, E. S., \& Ladd, G. W. (2001). Peer rejection as antecedent of young children's school adjustment: An examination of mediating processes. Developmental psychology, 37(4), 550-560, https://doi.org/10.1037/0012-1649.37.4.550

Cacioppo, J. T., \& Patrick, W. (2008). Loneliness: Human nature and the need for social connection. New York, NY: W.W. Norton \& Company.

Çağlar, Ç. (2013). The Relationship between the Perceptions of the Fairness of the Learning Environment and the Level of Alienation. Eurasian Journal of Educational Research, 50, 185-206.

Chen, F. F. (2007). Sensitivity of goodness of fit indexes to lack of measurement invariance. Structural equation modeling, 14(3), 464-504. 
Coie, J. D., Dodge, K. A., \& Kupersmidt, J. B. (1990). Peer group behavior and social status. In S. R. Asher \& J. D. Coie (Ed.), Peer rejection in childhood (pp. 17-59). Cambridge, UK: Cambridge University Press.

Dekel, R., \& Tuval-Mashiach, R. (2012). Multiple losses of social resources following collective trauma: The case of the forced relocation from Gush Katif. Psychological Trauma: Theory, Research, Practice and Policy, 4(1), 56-65, https://doi.org/10.1037/a0019912

Eccles, J. S., \& Alfeld, C. A. (2007). Not you! Not here! Not now. In R. K. Silbereisen \& R. M. Lerner (Eds.), Approaches to positive youth development (pp. 133-156). Thousand Oaks, CA: Sage.

Eccles, J., \& Gootman, J. A. (2002). Community programs to promote youth development. Washington, DC: National Academy Press, https://doi.org/10.17226/10022

Farrow, J. A. (1991). Youth alienation as an emerging pediatric health care issue. American Journal of Diseases of Children, 145(5), 491-492, https://doi.org/10.1001/archpedi.1991.02160050015002

Fenzel, L. M. (2000). Prospective study of changes in global self-worth and strain during the transition to middle school. Journal of Early Adolescence, 20, 93-116.

Field, S., \& Hoffman, A. (1999). The importance of family involvement for promoting self-determination in adolescents with autism and other developmental disabilities. Focus on Autism and Other Developmental Disabilities, 14(1), 36-41.

Gazelle, H., \& Druhen, M. J. (2009). Anxious solitude and peer exclusion predict social helplessness, upset affect, and vagal regulation in response to behavioral rejection by a friend. Developmental Psychology, 45(4), 10771096, https://doi.org/10.1037/a0016165

Ghaith, G. M., Shaaban, K. A., \& Harkous, S. A. (2007). An investigation of the relationship between forms of positive interdependence, social support, and selected aspects of classroom climate. System, 35(2), 229-240.

Gonzalez-DeHass, A. R., Willems, P. P., \& Holbein, M. F. D. (2005). Examining the relationship between parental involvement and student motivation. Educational psychology review, 17(2), 99-123.

Gottfried, A. E., Fleming, J. S., \& Gottfried, A. W. (1998). Role of cognitively stimulating home environment in children's academic intrinsic motivation: A longitudinal study. Child development, 69(5), 1448-1460.

Greenberg, M. T., Siegel, J. M., \& Leitch, C. J. (1983). The nature and importance of attachment relationships to parents and peers during adolescence. Journal of youth and adolescence, 12(5), 373-386.

Grob, A., Wearing, A. J., Little, T. D., \& Wanner, B. (1996). Adolescents' well-being and perceived control across 14 sociocultural contexts. Journal of Personality and Social Psychology, 71(4), 785-795.

Guerra, N. G., Huesmann, R., Tolan, P., VanAcker, R., \& Eron, L. D. (1995). Stressful events and individual beliefs as correlates of economic disadvantage and ag gression among urban children. Journal of Consulting and Clinical Psychology, 63, 518-528.

Hadjar, A., \& Lupatsch, J. (2010). Der Schul(miss)erfolg der Jungen. Kölner Zeitschrift für Soziologie und Sozialpsychologie, 62(4), 599-622.

Hall-Lande, J.A., Eisenberg, M.E., Christenson, S.L., \& Neumark-Sztainer, D. (2007). Social isolation, psychological health, and protective factors in adolescence. Adolescence, 42(166), 265-286.

Harter, S., Whitesell, N. R., \& Kowalski, P. (1992). Individual differences in the effects of educational transitions on young adolescent's perceptions of competence and motivational orientation. American Educational Research Journal, 29(4), 777-807.

Hascher, T. (2003). Well-being in school: Why students need social support. In P. Mayring \& C. von Rhöneck (Eds.), Learning emotions - The influence of affective factors on classroom learning (pp. 127-142). Bern, Switzerland: Lang.

Hascher, T. (2007). Exploring students' well-being by taking a variety of looks into the classroom. Hellenic Journal of Psychology, 4(3), 331-349.

Hascher, T. (2010). Wellbeing. In P. Peterson, E. Baker \& B. McGaw (Eds.), International Encyclopedia of Education (pp. 732-738). Oxford: Elsevier.

Hascher, T. (2011). Wellbeing. In S. Järvelä (Ed.), Social and emotional aspects of learning (pp. 99-105). Oxford: Elsevier.

Hascher, T. (2012). Well-being and learning in school. In N. M. Seel (Ed.), Encyclopedia of the Sciences of Learning (pp. 3453-3456). Heidelberg: Springer.

Hascher, T., \& Hadjar, A. (2017). School Alienation - A review of theoretical approaches and educational research. SASAL-Manuscript, University of Bern/University of Luxembourg.

Hascher, T., \& Hagenauer, G. (2010). Alienation from school. International journal of educational research, 49(6), 220-232.

Heimer, K., \& Matsueda, R. L. (1997). A symbolic interactionist theory of motivation and deviance: Interpreting psychological research. In D. W. Osgood (Ed.), Motivation and delinquency. Lincoln, NE: University of Nebraska Press.

Homburg, C. \& Baumgartner, H. (1995). Beurteilung von Kausalmodellen: Bestandsaufnahme und Anwendungsempfehlungen. Marketing: Zeitschrift für Forschung und Praxis, 17(3), 162-176.

Hu, L. T., \& Bentler, P. M. (1999). Cutoff criteria for fit indexes in covariance structure analysis: Conventional criteria versus new alternatives. Structural equation modeling: a multidisciplinary journal, 6(1), 1-55. 
Hyman, I., Cohen, I., \& Mahon, M. (2003). Student Alienation Syndrome: A paradigm for understanding the relation between school trauma and school violence. The California School Psychologist, 8(1), 73-86.

Ifeagwazi, C. M., Chukwuorji, J. C., \& Zacchaeus, E. A. (2015). Alienation and psychological wellbeing: Moderation by resilience. Social Indicators Research, 120(2), 525-544, https://doi.org/10.1007/s11205014-0602-1

Jonge, J., Dormann, C., Janssen, P. P., Dollard, M. F., Landeweerd, J. A., \& Nijhuis, F. J. (2001). Testing reciprocal relationships between job characteristics and psychological well-being: A cross-lagged structural equation model. Journal of occupational and organizational psychology, 74(1), 29-46.

Kagan, D. M. (1990). How schools alienate students at risk: A model for examining proximal classroom variables. Educational Psychologist, 25, 105-125, https://doi.org/10.1207/s15326985ep2502_1

Konu, A., \& Rimpelä, M. (2002). Well-being in schools: a conceptual model. Health promotion international, $17(1), 79-87$.

La Greca, A. M., \& Harrison, H. M. (2005). Adolescent peer relations, friendships, and romantic relationships: Do they predict social anxiety and depression? Journal of clinical child and adolescent psychology, 34(1), 4961.

Leduc, C., \& Bouffard, T. (2017). The impact of biased self-evaluations of school and social competence on academic and social functioning. Learning and Individual Differences, 55, 193-201, https://doi.org/10.1016/j.lindif.2017.04.006

Little, T. D. (2013). Longitudinal structural equation modeling. Guilford Press.

Mayring, P. (1991). Die Erfassung subjektiven Wohlbefindens. In A. Abele \& P. Becker (Eds.), Wohlbefinden (pp. 51-70). Weinheim: Juventa.

McGregor, I., \& Little, B. R. (1998). Personal projects, happiness, and meaning: on doing well and being yourself. Journal of personality and social psychology, 74(2), 494-512.

Milfont, T. L., \& Fischer, R., (2010). Testing measurement invariance across groups: Applications in cross-cultural research. International Journal of psychological research, 3(1), 111-121.

Moreno, E. S., \& de Roda, A. B. L. (2003). Social psychology of mental health: The social structure and personality perspective. The Spanish Journal of Psychology, 6(1), 3-11.

Moriarty, A., \& McDonald, S. (1991). Theoretical dimensions of school-based mediation. Children \& Schools, 13(3), 176-184.

Morinaj, J., Scharf, J., Grecu, A., Hadjar, A., Hascher, T., \& Marcin, K. (2017). School Alienation: A Construct Validation Study. Frontline Learning Research, 5(2), 36-59, http://doi.org/10.14786/flr.v5i2.298

Murdock, T. B. (1999). The social context of risk. Journal of Educational Psychology, 91(1), 62-75.

Muthén, L. K., \& Muthén, B. O. (1998-2012). Mplus user's guide (7th ed.). Los Angeles, CA: Muthén \& Muthén.

Newsom, J. T. (2015). Longitudinal structural equation modeling: A comprehensive introduction. New York, NY: Routledge.

Noble, T., \& McGrath, H. (2016). The PROSPER School Pathways for Student Wellbeing: Policy and Practices. New York: Springer International Publishing, https://doi.org/10.1186/s13612-015-0030-2

Nutbeam, D., Smith, C., Moore, L., \& Bauman, A. (1993). Warning! Schools can damage your health: alienation from school and its impact on health behaviour. Journal of paediatrics and child health, 29(1), 25-30.

OECD. (2016). Education at a Glance 2016: OECD Indicators. Paris: OECD Publishing, https://doi.org/10.1787/eag-2016-en

OECD. (2017). PISA 2015 Results Volume III: Students' Well-Being. Paris: OECD Publishing, https://doi.org/10.1787/9789264273856-en

Ong, A. D., \& van Dulmen, M. H. (2006). Oxford handbook of methods in positive psychology. New York, NY: Oxford University Press.

Osin, E. (2009). Subjective experience of alienation: Measurement and correlates. Gesellschaft für Logotherapie und Existenzanalyse, 1(26), 16-23.

Pinquart, M., \& Sörensen, S. (2000). Influences of socioeconomic status, social network, and competence on subjective well-being in later life: a meta-analysis. Psychology and Aging, 15(2), 187-224.

Prager, K. J., \& Steil, J. M. (1997). Intimacy and Well-being. Psyccritiques, 42(4), 302, https://doi.org/10.1037/000434

Prinstein, M. J., Boergers, J., \& Vernberg, E. M. (2001). Overt and relational aggression in adolescents: Socialpsychological adjustment of aggressors and victims. Journal of Clinical Child Psychology, 30, 479-491, https://doi.org/10.1207/S15374424JCCP3004_05

Pyhältö, K., Soini, T., \& Pietarinen, J. (2010). Pupils' pedagogical well-being in comprehensive school significant positive and negative school experiences of Finnish ninth graders. European Journal of Psychology of Education, 25(2), 207-221.

Rayce, S. L., Holstein, B. E., \& Kreiner, S. (2008). Aspects of alienation and symptom load among adolescents. The European Journal of Public Health, 19(1), 79-84.

Reis, H. T., \& Shaver, P. (1988). Intimacy as an interpersonal process. Handbook of personal relationships, 24(3), 367-389. 
Reis, H. T., Sheldon, K. M., Gable, S. L., Roscoe, J., \& Ryan, R. M. (2000). Daily well-being: The role of autonomy, competence, and relatedness. Personality and social psychology bulletin, 26(4), 419-435.

Rice, K. G., Cunningham, T. J., \& Young, M. B. (1997). Attachment to parents, social competence, and emotional well-being: A comparison of Black and White late adolescents. Journal of Counseling Psychology, 44(1), 89-101.

Ryan, R. M., \& Deci, E. L. (2000). Self-determination theory and the facilitation of intrinsic motivation, social development, and well-being. American psychologist, 55(1), 68-78, https://doi.org/10.1037110003066X.55.1.68

Ryan, R. M., \& Deci, E. L. (2001). On happiness and human potentials: A review of research on hedonic and eudaimonic well-being. Annual review of psychology, 52(1), 141-166.

Safipour, J., Schopflocher, D., Higginbottom, G., \& Emami, A. (2011). The mediating role of alienation in selfreported health among Swedish Adolescents. http://www.tandfonline.com/doi/pdf/10.3402/vgi.v2i0.5805?needAccess=true. Accessed 21 Februar 2017.

Satorra, A., \& Bentler, P. M. (2001). A scaled difference chi-square test statistic for moment structure analysis. Psychometrika, 66(4), 507-514.

Schermelleh-Engel, K., Moosbrugger, H., \& Müller, H. (2003). Evaluating the fit of structural equation models: Tests of significance and descriptive goodness-of-fit measures. Methods of psychological research online, $8(2), 23-74$

Selig, J. P., \& Little, T. D. (2012). Autoregressive and cross-lagged panel analysis for longitudinal data. In B. Laursen \& T.D. Little (Eds.), Handbook of developmental research methods (pp. 265-278). New York, NY: Guilford Press.

Seligman, M. E., Ernst, R. M., Gillham, J., Reivich, K., \& Linkins, M. (2009). Positive education: Positive psychology and classroom interventions. Oxford review of education, 35(3), 293-311.

Sher, K. J., Wood, M. D., Wood, P. K., \& Raskin, G. (1996). Alcohol outcome expectancies and alcohol use: a latent variable cross-lagged panel study. Journal of abnormal psychology, 105(4), 561-574.

Sidorkin, A. M. (2004). In the event of learning: Alienation and participative thinking in education. Educational Theory, 54(3), 251-262.

Tinto, V. (1975). Dropout from higher education: A theoretical synthesis of recent research. Review of Educational Research, 45(1), 89-125.

Tinto, V. (1993). Leaving college: Rethinking the causes of student attrition. Chicago: University of Chicago Press.

UNESCO. (2016). Happy Schools! A Framework for Learner Well-Being in the Asia-Pacific. http://unesdoc.unesco.org/images/0024/002441/244140E.pdf. Accessed 20 August 2017.

Vahedi, S., \& Nazari, M. A. (2011). The relationship between self-alienation, spiritual well-being, economic situation and satisfaction of life: A structural equation modeling approach. Iranian Journal of Psychiatry and Behavioral Sciences, 5(1), 64-73.

Wentzel, K. R., McNamara-Barry, C., \& Caldwell, K. A. (2004). Friendships in middle school: Influences on motivation and school adjustment. Journal of Educational Psychology, 96, 195-203.

Yonah, Y. (1997). Patriotism, Alienation, and Well-Being: Rousseau on Political Legitimacy. Iyyun: The Jerusalem Philosophical Quarterly, 293-326. 